\title{
Patient Preferences and Values in Decision Making for Migraines: A Systematic Literature Review
}

\author{
Xianpeng Xu $\left(\mathbb{D},{ }^{1}\right.$ Qingjie Ji $\mathbb{D}^{1},{ }^{1}$ and Min Shen $\mathbb{D}^{2}$ \\ ${ }^{1}$ Department of Acupuncture and Moxibustion, Quzhou Hospital of Traditional Chinese Medicine, Quzhou, China \\ ${ }^{2}$ Department of Neurology, The First Affiliated Hospital of Zhejiang Chinese Medical University, Hangzhou, China
}

Correspondence should be addressed to Min Shen; 1099925193@qq.com

Received 12 March 2021; Revised 31 July 2021; Accepted 28 August 2021; Published 17 September 2021

Academic Editor: Sreekanth Kumar Mallineni

Copyright (c) 2021 Xianpeng Xu et al. This is an open access article distributed under the Creative Commons Attribution License, which permits unrestricted use, distribution, and reproduction in any medium, provided the original work is properly cited.

Objective. To comprehensively summarize the evidence on the preferences and values of migraine patients. Methods. We searched PubMed, Embase, Web of Science, China National Knowledge Infrastructure, Sino-Med, Chongqing VIP, and Wanfang Data for studies on the preferences and values of migraine patients. A qualitative review was performed, but no quantitative synthesis. Results. Twenty-one studies were finally included, involving a total of 8701 participants. Patients expected a cure, to be symptomfree, a reduction in frequency of headaches, a reduction in severity of headaches, and an improved quality of life from their preventive treatment. Patients expected rapid pain relief, complete pain relief, return to normal activities, no recurrence, and no adverse events from their acute symptomatic treatment. Conclusion. Efficacy is the primary consideration in the treatment of migraine. Specifically, the most important embodiment of patient preferences and values is the reduced frequency of attacks with preventive treatment as well as prompt analgesia with acute symptomatic treatment.

\section{Introduction}

Patient preferences and values are mostly convergent with those of healthcare workers, but there are also differences [1]. As direct recipients in the process of disease diagnosis and treatment, the preferences and values of patients cannot be ignored [2]. Patients themselves have expressed interest in the decision-making process, and their adherence to treatment can be simultaneously improved when they participate in the decision-making process $[3,4]$. Evidence-based medicine states that optimal clinical decisions should take into account the experience of clinicians, clinical research evidence, and patient preferences and values [5]. Furthermore, evidence of patient preferences and values has also been emphasized in the development of guidelines [6-10].

Migraine is the third most prevalent disorder and the first cause of disability [11]. Current mainstay of migraine treatment is drugs, including prophylactic and analgesic drugs [12]. The use of prophylactic drugs aims to lessen the frequency and severity of the migraine attacks, and the common prophylactic drugs include antihypertensives (e.g., $\beta$-blockers, calcium channel blockers, and angiotensinconverting enzyme inhibitors), antidepressants, anticonvulsants, and antihistamines [12]. The use of analgesic drugs aims to prevent a migraine attack or to stop it once it starts, and the common analgesic drugs include triptans, nonsteroidal anti-inflammatory drugs, acetaminophen, combination (acetaminophen, caffeine, and aspirin), and narcotics [13]. Other treatments such as application of pressure, cold, or heat, acupuncture, and surgical treatment have also gradually attracted attention in recent years, but evidence support is still lacking [14].

According to the Grading of Recommendations, Assessment, Development, and Evaluation approach, patient preferences and values refer to the relative importance of the patient for the outcome or health state of interest [9]. Based on the experience of guideline experts [10], we defined patient preferences and values as the perspectives, expectations, and goals of patients regarding treatment attributes. Treatment attributes were divided into treatment process 
attributes and outcome attributes. Among them, treatment process attributes included treatment strategy, duration, route of administration, formulation, and cost; treatment outcome attributes included treatment benefits and side effects [10]. There had been a significant increase in the number of studies investigating the preferences and values in patients with migraines; to comprehensively summarize the evidence, we carried out this systematic literature study.

\section{Methods}

2.1. Eligibility Criteria. Inclusion criteria were as follows: studies related to patient preferences and values for migraine therapy, both the preventive treatment and the acute symptomatic treatment; studies that examined the context of the consideration of migraine therapy and how patients value alternative health states and experiences with treatment; and studies that examined the choices patients make when presented with decisional aids for management options regarding migraine therapy. The exclusion criteria were reviews, letters, posters, case reports, and case series.

2.2. Data Sources and Search Strategy. PubMed, Embase, Web of Science, China National Knowledge Infrastructure, Sino-Med, Chongqing VIP, and Wanfang Data were searched from their inception to August 2020. Search terms included migraine, patient preferences, patient values, and health attitude. Table 1 provides a search strategy for the Embase database.

2.3. Study Selection and Data Extraction. Two investigators independently read titles, abstracts, and full text to identify eligible studies. Any conflicts were adjudicated through discussion. According to the characteristics of the included studies, we extracted the following basic information using a standardized data extraction form: the first author, year of publication, date of study conduction, type of study, number of patients, and their demographics (mean age, gender), treatment protocol, methods used for evaluating patient preferences and values, outcomes assessed, main results, and methodological characteristics.

2.4. Quality Assessment. An evaluation of the quality of the included studies was performed with the instrument recommended by the Agency for Healthcare Research and Quality (AHRQ) [15]. There were 11 items in the AHRQ checklist, and each item was evaluated using three evaluation options, yes (scored "1"), unclear (scored "0"), or no (scored "0"). The quality was classified into three levels: low quality $=0-3$; moderate quality $=4-7$; high quality $=8-11[16]$.

2.5. Statistical Analysis. A qualitative review was performed, but no quantitative synthesis. The results are presented in tabular form.

\section{Results}

3.1. Results of Included Studies. A total of 3774 articles were acquired from the electronic search, and 405 duplicates were excluded. After screening the titles and abstracts, 3259 articles were excluded. Afterwards, the full texts of the remaining 110 articles were read for further evaluation, and 89 articles were excluded. Finally, a total of 21 studies [17-37] were ultimately included. The selection process is shown in Figure 1.

Characteristics of the studies, including date of study conduction, country, study design, simple size, migraine status, treatments, methods of stated-preference assessment, and methodological quality of the studies, are shown in Table 2. The most commonly used methods for evaluating patient preferences and values are described briefly in Table 3.

3.2. The Preventive Treatment for Migraine. Preferences and values for preventive treatment were reported in seven studies [17-23]. In general, all patients attached great importance to the preventive treatment of migraine. For treatment process, therapies with higher response rates, fewer adverse events, less frequent dosing regimens, and higher convenience were preferred $[17,18,20,22]$. For treatment outcome, patients expected a cure, to be symptom-free, a reduction in frequency of headaches, a reduction in severity of headaches, and an improved quality of life from their treatment $[18,20,21]$. Efficacy was the most important aspect of outcome in preventive treatment; some patients even did not mind taking more than one preventive agent at one time if greater efficacy could be achieved [22]. The preventive treatment for migraine was important; however, not all patients actually used this treatment [19]. More details are shown in Table 4.

\subsection{Acute Symptomatic Treatment for Migraine.} Preferences and values for acute symptomatic treatment were reported in 14 studies [24-37]. For treatment process, therapies with a faster onset of action, a longer duration of the effects, fewer adverse events, and lower price were preferred [26-35, 37]. Triptans were the most commonly used drugs, and the order of priority for dosage form of triptans was tablets, nasal spray, and subcutaneous injection $[24,27,30]$. For treatment outcome, patients expected rapid pain relief, complete pain relief, return to normal activities, no recurrence, and no adverse events from their treatment [24, 27-37]. More details are shown in Table 5.

\section{Discussion}

A literature search yielded several published studies on preferences and values among patients with migraines. In this research, we systematically evaluated studies reporting the preferences and values of patients with migraines, thus providing summarized evidence for clinicians. 
TABLe 1: Search strategy for Embase.

\begin{tabular}{|c|c|}
\hline Query & Search term \\
\hline$\# 1$ & "Migraine"/exp \\
\hline$\# 2$ & “Migraine":ab, ti OR “migraines":ab, ti OR “status migrainosus":ab, ti OR “sick headache”:ab, ti OR "sick headaches": ab, ti \\
\hline \#3 & \#1 OR \#2 \\
\hline \#4 & "Patient preference"/exp \\
\hline \#5 & 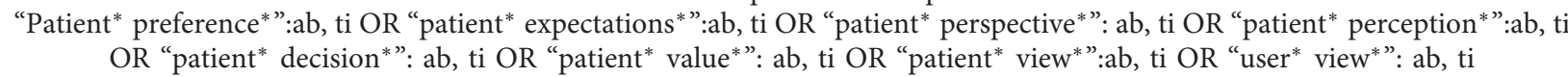 \\
\hline \#6 & "Attitude to health"/exp \\
\hline \#7 & "Attitude to health": ab, ti OR "health attitude*": ab, ti \\
\hline \#8 & \#4 OR \#5 OR \#6 OR \#7 \\
\hline \#9 & \#3 AND \#8 \\
\hline
\end{tabular}
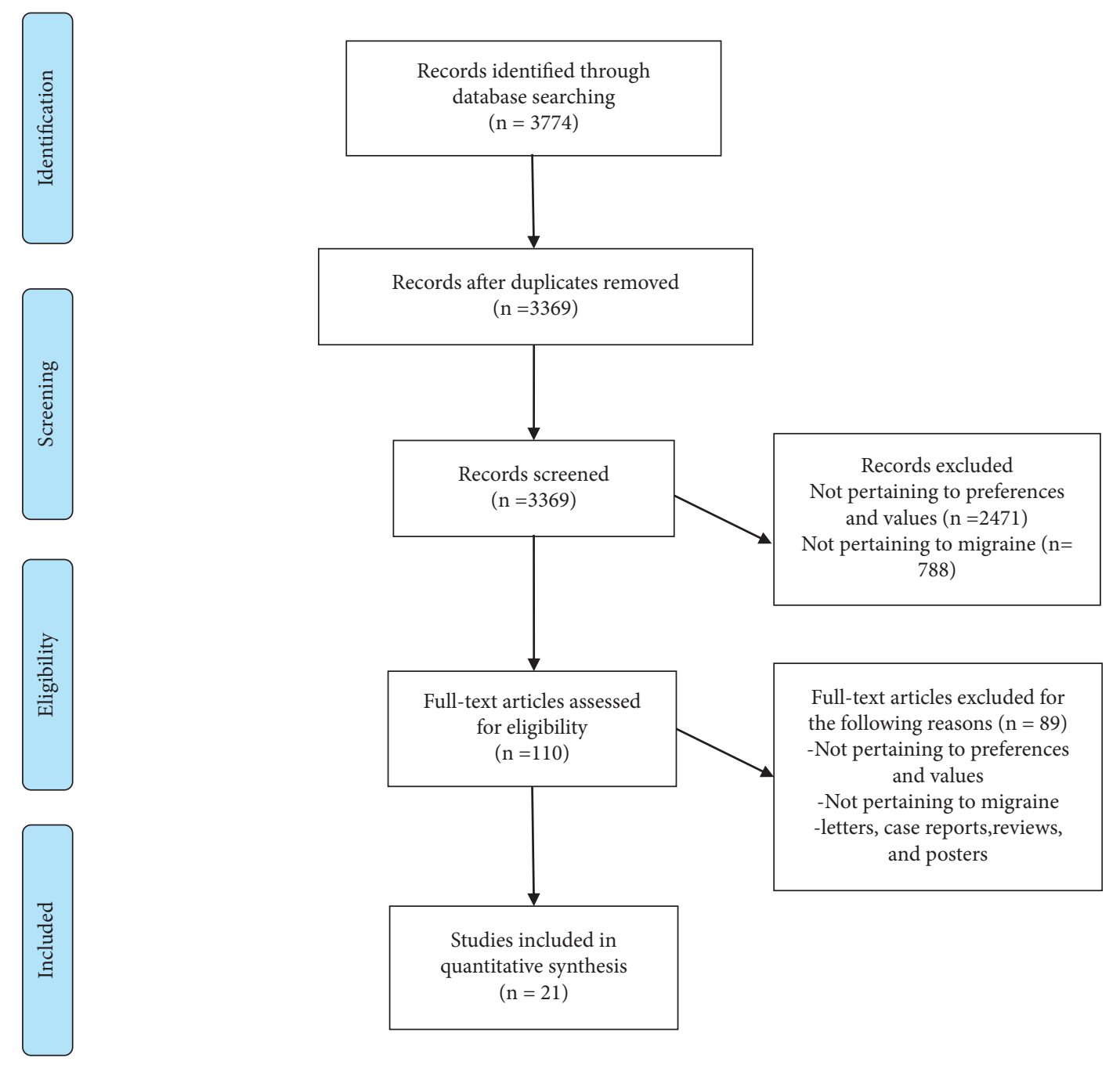

FIgURE 1: Flow diagram of the selection process.

4.1. Summary of Main Findings. In this review, 21 studies enrolled 8701 participants were final included. In summary, evidence from these included studies suggested that the efficacy was the primary consideration in the treatment of migraine. For preventive treatment, therapies with higher response rates, fewer adverse events, less frequent dosing regimens, and higher convenience were preferred. Patients expected a cure, to be symptom-free, a reduction in frequency of headaches, a reduction in severity of headaches, and an improved quality of life from their preventive treatment. For acute symptomatic treatment, therapies with a faster onset of action, a longer duration of the effects, fewer adverse events, and lower price were preferred. Patients expected rapid pain relief, complete pain relief, return to normal activities, no recurrence, and no adverse events from their acute symptomatic treatment. Moreover, triptans were 


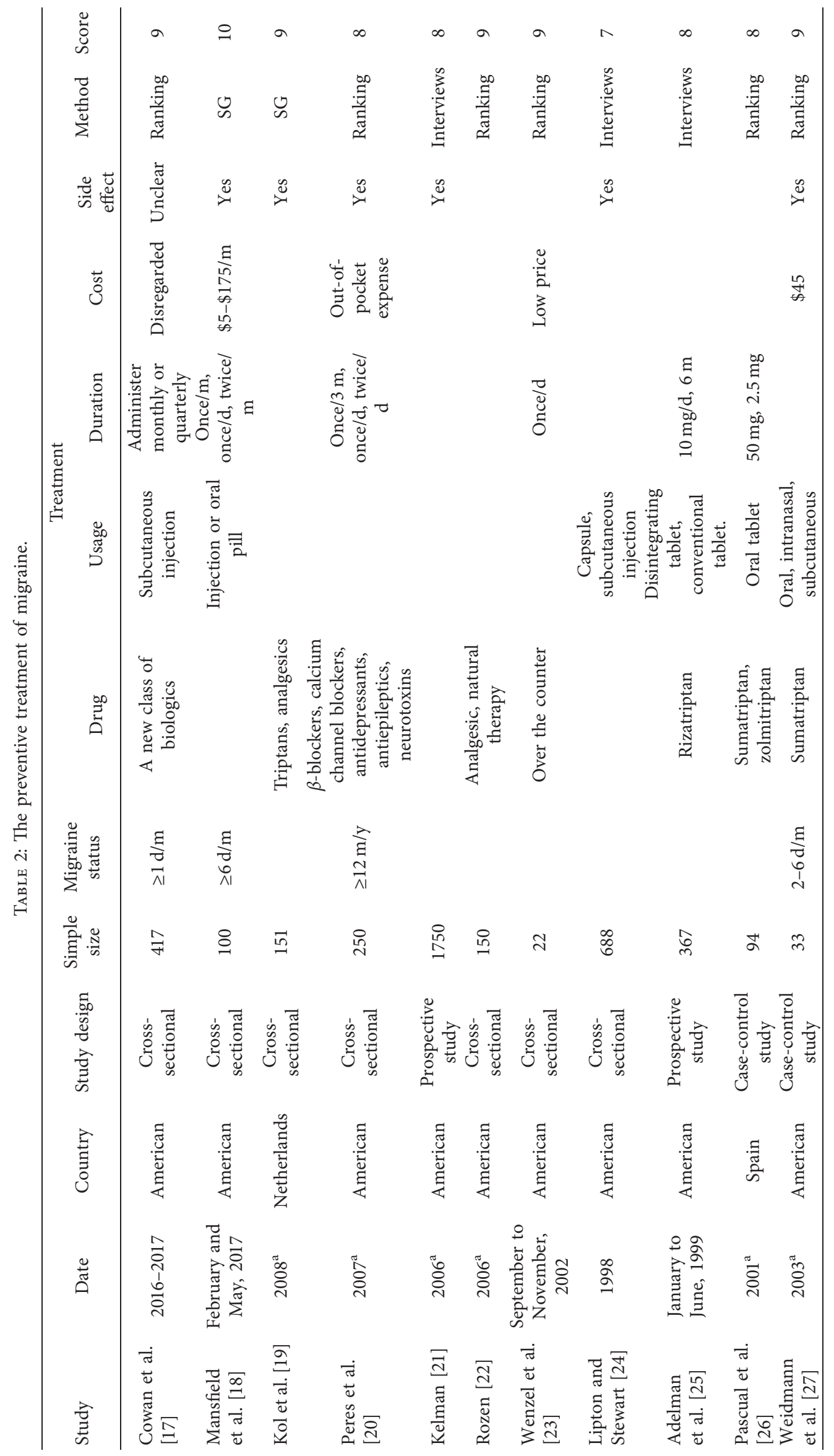




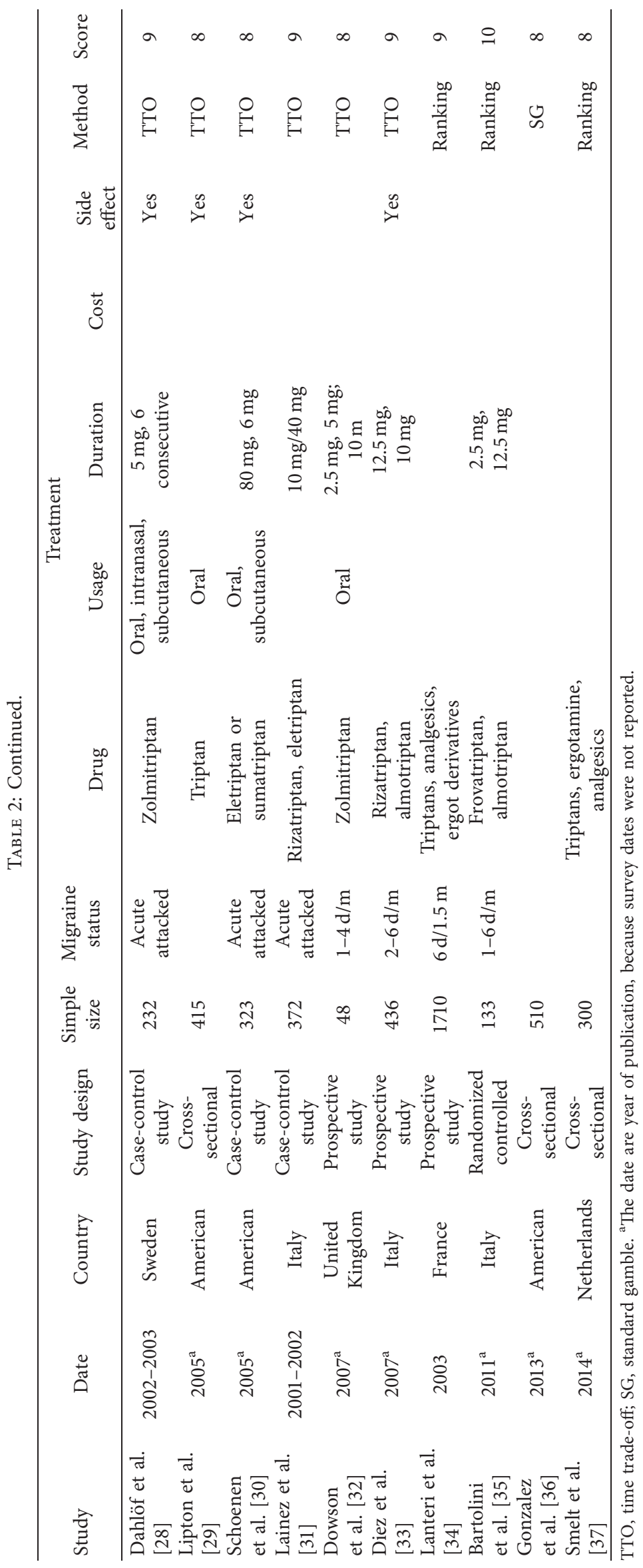


TABLE 3: Description of the main methods used for evaluating patient preferences and values.

\begin{tabular}{|c|c|c|}
\hline Name & Description & Example \\
\hline Ranking & $\begin{array}{l}\text { Researchers ask patients to rate a set of outcomes on an } \\
\text { ordered "Likert-type" scale (rating) or to rank them from the } \\
\text { most to the least important. Rating can also use visual analog } \\
\text { scale and in this case utilities can be derived }\end{array}$ & $\begin{array}{l}\text { From Ref. [17]: "patients were ranked on a seven-point scale, } \\
\text { with } 1 \text { being "not at all likely" and } 7 \text { being "extremely likely," } \\
\text { their likelihood of acceptance of and adherence to the new } \\
\text { medication in scenarios in which either monthly or quarterly } \\
\text { dosing is available" }\end{array}$ \\
\hline $\begin{array}{l}\text { Time trade- } \\
\text { off }\end{array}$ & $\begin{array}{l}\text { Researchers ask patients to choose between the health states } \\
\text { as described in a clinical scenario during } X \text { years and a } \\
\text { shorter life in normal health. The duration } X \text { is varied until } \\
\text { the patient is unable to choose between the two options }\end{array}$ & $\begin{array}{l}\text { From Ref. [30]: "three attacks were treated on each study } \\
\text { medication. Assessment of subjective preference was } \\
\text { evaluated, after which patients freely choose which study } \\
\text { medication they wished to use to treat each of the three } \\
\text { additional migraine attacks" }\end{array}$ \\
\hline $\begin{array}{l}\text { Standard } \\
\text { gamble }\end{array}$ & $\begin{array}{c}\text { Researchers ask patients to choose between two possible } \\
\text { outcomes: a suboptimal health state that is certain and a } \\
\text { gamble with one better (for example, full health) and one } \\
\text { worse (for example, death or side effects) outcome possible. } \\
\text { The probability of the gamble is varied during the } \\
\text { experiment and the point of indifference is used to derive the } \\
\text { utility of the health state }\end{array}$ & $\begin{array}{l}\text { From Ref. [18]: "respondents valued a change from a } 10 \% \\
\text { reduction in headache days per month to a } 50 \% \text { reduction } \\
\text { more highly than avoiding the worst levels of adverse events. } \\
\text { Nevertheless, respondents were willing to forgo some } \\
\text { improvements in efficacy for less-severe adverse events" }\end{array}$ \\
\hline
\end{tabular}

TABle 4: Preferences and values for preventive treatment.

\begin{tabular}{|c|c|c|}
\hline Study & Treatment process & Treatment outcome \\
\hline $\begin{array}{l}\text { Cowan et al. } \\
\text { [17] }\end{array}$ & $\begin{array}{l}\text { Most patients preferred monthly or quarterly dosing, } \\
\text { while a small proportion had no preference }\end{array}$ & \\
\hline $\begin{array}{l}\text { Mansfield } \\
\text { et al. }[18]\end{array}$ & $\begin{array}{l}\text { Patients tended to inject monthly or daily rather than } \\
\text { twice a month when treating }\end{array}$ & $\begin{array}{l}\text { It was more important to change the number of migraine attack } \\
\text { days from a } 10 \% \text { reduction to a } 50 \% \text { reduction than to avoid } \\
\text { adverse events }\end{array}$ \\
\hline Kol et al. [19] & $\begin{array}{l}\text { Fifty-five percent of patients wanted to use } \\
\text { prophylaxis; only } 8 \% \text { actually used this treatment }\end{array}$ & \\
\hline $\begin{array}{l}\text { Peres et al. } \\
{[20]}\end{array}$ & $\begin{array}{c}\text { Therapies with higher response rates, fewer adverse } \\
\text { events, and less frequent dosing regimens were } \\
\text { preferred }\end{array}$ & $\begin{array}{l}\text { Patients rated efficacy as the most important aspect of preventive } \\
\text { treatment outcome }\end{array}$ \\
\hline Kelman [21] & & $\begin{array}{c}\text { A percentage of } 95.2 \text { expected a reduction in frequency of } \\
\text { headaches from their treatment, } 95.6 \% \text { a reduction in severity of } \\
\text { pain, } 79.7 \% \text { to be symptom-free, } 27.8 \% \text { a cure, and } 95.5 \% \text { an } \\
\text { improved quality of life }\end{array}$ \\
\hline Rozen [22] & $\begin{array}{l}\text { If greater efficacy could be achieved, patients did not } \\
\text { mind using more than } 1 \text { prophylactic agent }\end{array}$ & \\
\hline $\begin{array}{l}\text { Wenzel et al. } \\
{[23]}\end{array}$ & & $\begin{array}{c}\text { The vast majority of patients wanted to use over-the-counter } \\
\text { drugs to effectively prevent migraine }\end{array}$ \\
\hline
\end{tabular}

the most commonly used drugs for acute symptomatic treatment, and the order of priority for dosage form of triptans was tablets, nasal spray, and subcutaneous injection.

4.2. Regimens for Migraines. Preventive treatment for migraines should be preemptive, short term, or maintained. Antiepileptic drugs, $\beta$-blockers, antidepressants, calcium channel antagonists, botulinum neurotoxins, and serotonin antagonists are the most commonly used drugs for migraine prevention [12]. On the basis of evidence-based medical evidence, the first-line medications identified as effective include topiramate, divalproex, propranolol, metoprolol, and timolol; the second-line medications identified as effective include venlafaxine, amitriptyline, nadolol, and atenolol [38]. For migraine prevention, $\beta$-blockers are the most widely used drugs, which can reduce the frequency of attacks by more than 50\%, and there are no absolute or relative contraindications [39]. Tricyclic antidepressants are also used to prevent migraines; however, only amitriptyline has proven efficacy in migraine. In addition, the high incidence of adverse events limits its use [40]. Since the efficacy of placebo-controlled trials has been confirmed, antiepileptic drugs are increasingly recommended for migraine. However, it is worth noting that most antiepileptic drugs may substantially interfere with the efficacy of oral contraceptives [41]. Furthermore, other medications such as calcium channel blockers, angiotensin-converting enzyme inhibitors, angiotensin receptor blockers, onabotulinumtoxinA, and complementary and alternative medicines cannot be recommended for migraine prevention due to the limited evidence quality [38].

For acute symptomatic treatment, the first-line medications for mild to moderate migraine are acetaminophen and nonsteroidal anti-inflammatory drugs, whereas triptans for moderate to severe migraines; for those with refractory migraine, dihydroergotamine and antiemetics are recommended for use as second- or third-line medications [42]. 
TABLe 5: Preferences and values for acute symptomatic treatment.

\begin{tabular}{|c|c|c|}
\hline Study & Treatment process & Treatment outcome \\
\hline $\begin{array}{l}\text { Lipton and } \\
\text { Stewart [24] }\end{array}$ & $\begin{array}{l}\text { In terms of dosage form, the order of priority was tablets, } \\
\text { nasal spray, and subcutaneous injection }\end{array}$ & $\begin{array}{l}\text { Eighty-seven percent of patients had expected complete } \\
\text { pain relief after treatment, } 86 \% \text { had no recurrence, and } \\
\qquad 83 \% \text { had rapid pain relief }\end{array}$ \\
\hline $\begin{array}{l}\text { Adelman et al. } \\
{[25]}\end{array}$ & $\begin{array}{c}\text { Among the included patients, } 188 \text { chose orally } \\
\text { disintegrating tablets, while } 179 \text { preferred conventional } \\
\text { tablets }\end{array}$ & \\
\hline $\begin{array}{l}\text { Pascual et al. } \\
{[26]}\end{array}$ & $\begin{array}{l}\text { The reasons for patient preference for either of the two } \\
\text { triptans were faster onset, duration of action, fewer adverse } \\
\text { events, and lower price }\end{array}$ & \\
\hline $\begin{array}{l}\text { Weidmann et al. } \\
\text { [27] }\end{array}$ & $\begin{array}{l}\text { In terms of dosage form, the order of priority was tablets, } \\
\text { nasal spray, and subcutaneous injection }\end{array}$ & Rapid pain relief without adverse events \\
\hline Dahlöf et al. [28] & $\begin{array}{c}\text { Most patients would like to continue using zolmitriptan } \\
\text { nasal spray }\end{array}$ & Rapid pain relief without adverse events \\
\hline Lipton et al. [29] & $\begin{array}{l}\text { When selecting a triptan, the rating of efficacy attributes was } \\
\text { clearly more important than tolerability or consistency }\end{array}$ & $\begin{array}{l}\text { Absence of pain within } 1 \text { hour was the most desired } \\
\text { treatment outcome for migraine patients }\end{array}$ \\
\hline $\begin{array}{l}\text { Schoenen et al. } \\
{[30]}\end{array}$ & More patients preferred eletriptan & Rapid pain relief without recurrence \\
\hline Lainez et al. [31] & $\begin{array}{l}\text { More patients preferred rizatriptan } 10 \mathrm{mg} \text { wafer compared } \\
\text { to eletriptan } 40 \mathrm{mg} \text { tablets }\end{array}$ & Rapid pain relief and return to normal activities \\
\hline $\begin{array}{l}\text { Dowson et al. } \\
\text { [32] }\end{array}$ & $\begin{array}{c}\text { At baseline, most patients indicated a preference for } \\
\text { conventional tablets. After trying other formulations with a } \\
\text { faster onset of action, most patients no longer preferred } \\
\text { conventional tablets }\end{array}$ & Rapid pain relief \\
\hline Diez et al. [33] & $\begin{array}{l}\text { More patients preferred almotriptan } 12.5 \mathrm{mg} \text { compared to } \\
\text { rizatriptan } 10 \mathrm{mg}\end{array}$ & Rapid pain relief and return to normal activities \\
\hline $\begin{array}{l}\text { Lanteri et al. } \\
{[34]}\end{array}$ & $\begin{array}{l}\text { Patients tended to use triptans and were satisfied with this } \\
\text { treatment }\end{array}$ & Freedom from pain and rapid onset of action \\
\hline $\begin{array}{l}\text { Bartolini et al. } \\
{[35]}\end{array}$ & Most of the patients indicated a preference for triptans & Rapid pain relief without recurrence \\
\hline $\begin{array}{l}\text { Gonzalez et al. } \\
\text { [36]. }\end{array}$ & & No recurrence of headache \\
\hline Smelt et al. [37] & & $\begin{array}{l}\text { Patients wanted to relieve pain within } 30 \text { minutes after } \\
\text { treatment, returned to normal activity within } 1 \text { hour, and } \\
\text { had no recurrence of headache }\end{array}$ \\
\hline
\end{tabular}

The use of acetaminophen and nonsteroidal anti-inflammatory drugs for mild to moderate migraine attacks is supported by strong evidence [42]. Moreover, nonsteroidal anti-inflammatory drugs have better efficacy than acetaminophen, but can cause gastric irritation or antiplatelet effects [43]. Triptans share a common mechanism of action and have strong evidence of effectiveness for moderate to severe migraine attacks [43]. However, different types of triptans have different routes of administration and kinetics, and they may be expensive [44]. Hence, appropriate individualized use is essential. Furthermore, other medications such as dihydroergotamine, opioids, and antiemetics have good evidence of effectiveness for migraine. However, they are reserved as second-line drugs due to adverse effects, abuse potential, route of administration, or cost [42].

4.3. Limitations. To the best of our knowledge, this is the first study to summary the evidence on the preferences and values of migraine patients. However, limitations should be acknowledged. First, the definition and eligibility criteria for preferences and values are broad; the lack of standardized methods for reporting and identifying the evidence of patient preferences places additional limitations on our research. Second, it is tentative and empirical to use a systematic literature review method to summary evidence; there might be nonrigorous and inconsistent phenomena.

\section{Conclusions}

In summary, evidence from these included studies suggests that the efficacy is the primary consideration in the treatment of migraine. Specifically, the most important embodiment of patient preferences and values is the reduced frequency of attacks with preventive treatment as well as prompt analgesia with acute symptomatic treatment.

\section{Abbreviations}

ODT: Orally disintegrating tablet

TTO: Time trade-off

SG: Standard gamble.

\section{Data Availability}

All data generated or analyzed during this study are included in this published article. 


\section{Conflicts of Interest}

The authors declare no potential conflicts of interest.

\section{Authors' Contributions}

Xianpeng Xu, Qingjie Ji, and Min Shen participated in the design of the study and drafted the manuscript. All authors read and approved the final manuscript.

\section{References}

[1] R. Xie, Y. L. Chen, H. Chen, Q. Wang, S. D. Zhai, and R. S. Zhao, "Research methods of patient values and preferences in the development of evidence-based guidelines," Chinese Journal of Evidence-Based Medicine, vol. 15, no. 5, pp. 586-591, 2015.

[2] S. E. Strauss, Evidence-based Medicine: How to Practice and Teach EBM. Evidence-Based Medicine, pp. 819-825, Elsevier/ Churchill Livingstone, Amsterdam, Netherlands, 2005.

[3] D. Postmus, S. Richard, N. Bere, J. Hillege, E. Low, and F. Pignatti, "Eliciting individual patient preferences on the benefits and risks of cancer treatments: results from A survey conducted in myeloma patients," Value in Health, vol. 19, no. 7, p. A746, 2016.

[4] C. Dias-Barbosa, M.-M. Balp, K. Kulich, N. Germain, and D. Rofail, "A literature review to explore the link between treatment satisfaction and adherence, compliance, and persistence," Patient Preference and Adherence, vol. 6, pp. 39-48, 2012.

[5] R. Luckmann, "Evidence-based medicine: how to practice and teach EBM, 2nd edition: by david L. Sackett, sharon E. Straus, W. Scott richardson, william rosenberg, and R. Brian haynes, churchill livingstone, 2000," Journal of Intensive Care Medicine, vol. 16, no. 3, pp. 155-156, 2001.

[6] Institute of Medicine, G. Robin, M. Michelle, M. W. Dianne, G. Sheldon, and S. Earl, "Clinical practice guidelines we can trust," Port Journal of Nephrology and Hypertension, 2011.

[7] SIGN, SIGN 50: A Guideline Developer, Handbook, pp. 19-22, Scottish Intercollegiate Guidelines Network, Edinburgh, UK, 2011.

[8] J. L. Brożek, E. A. Akl, E. Compalati et al., "Grading quality of evidence and strength of recommendations in clinical practice guidelines part 3 of 3 . The GRADE approach to developing recommendations," Allergy, vol. 66, no. 5, pp. 588-595, 2011.

[9] Y. Zhang, P. A. Coello, J. Brożek et al., "Using patient values and preferences to inform the importance of health outcomes in practice guideline development following the GRADE approach," Health and Quality of Life Outcomes, vol. 15, no. 1, p. 52, 2017.

[10] S. MacLean, S. Mulla, E. A. Akl et al., "Patient values and preferences in decision making for antithrombotic therapy: a systematic review," Chest, vol. 141, no. 2, pp. e1S-e23S, 2012.

[11] GBD 2017 Disease and Injury Incidence and Prevalence Collaborators, "Global, regional, and national incidence, prevalence, and years lived with disability for 354 diseases and injuries for 195 countries and territories, 1990-2017: a systematic analysis for the Global Burden of Disease Study 2017," Lancet, vol. 392, no. 10159, pp. 1789-1858, 2018.

[12] D. W. Dodick, "Migraine," The Lancet, vol. 391, no. 10127, pp. 1315-1330, 2018.

[13] L. Mayans and A. Walling, "Acute migraine headache: treatment strategies," American Family Physician, vol. 97, no. 4, pp. 243-251, 2018.
[14] G. L. Peters, "Migraine overview and summary of current and emerging treatment options," American Journal of Managed Care, vol. 25, no. 2 Suppl, pp. S23-S34, 2019.

[15] A. Rostom, C. Dube, A. Cranney et al., Celiac Disease, Agency for Healthcare Research and Quality, Rockville, MD, USA, 2004, http://www.ncbi.nlm.nih.gov/books/NBK35156.

[16] X. Xu, W. Li, L. Qin, W. Yang, G. Yu, and Q. Wei, "Relationship between Helicobacter pylori infection and obesity in Chinese adults: a systematic review with meta-analysis," PLoS One, vol. 14, Article ID e0221076, 2019.

[17] R. Cowan, J. M. Cohen, E. Rosenman, and R. Iyer, "Physician and patient preferences for dosing options in migraine prevention," The Journal of Headache and Pain, vol. 20, no. 1, p. 50, 2019.

[18] C. Mansfield, D. J. Gebben, J. Sutphin et al., "Patient preferences for preventive migraine treatments: a discrete-choice experiment," Headache: The Journal of Head and Face Pain, vol. 59, no. 5, pp. 715-726, 2019.

[19] C. M. Kol, F. Dekker, A. K. Neven, W. J. Assendelft, and J. W. Blom, "Acceptance or rejection of prophylactic medicine in patients with migraine: a cross-sectional study," British Journal of General Practice, vol. 58, no. 547, pp. 98-101, 2008.

[20] M. F. P. Peres, S. Silberstein, F. Moreira et al., "Patients' preference for migraine preventive therapy," Headache: The Journal of Head and Face Pain, vol. 47, no. 4, pp. 540-545, 2007.

[21] L. Kelman, "The broad treatment expectations of migraine patients," The Journal of Headache and Pain, vol. 7, no. 6, pp. 403-406, 2006.

[22] T. D. Rozen, "Migraine prevention: what patients want from medication and their physicians (a headache specialty clinic perspective)," Headache: The Journal of Head and Face Pain, vol. 46, no. 5, pp. 750-753, 2006.

[23] R. G. Wenzel, J. C. Schommer, and T. G. Marks, "Morbidity and medication preferences of individuals with headache presenting to a community pharmacy," Headache: The Journal of Head and Face Pain, vol. 44, no. 1, pp. 90-94, 2004.

[24] R. B. Lipton and W. F. Stewart, "Acute migraine therapy: do doctors understand what patients with migraine want from therapy?" Headache: The Journal of Head and Face Pain, vol. 39, no. s2, pp. S20-S26, 1999.

[25] J. U. Adelman, L. K. Mannix, and R. L. Von Seggern, "Rizatriptan tablet versus wafer: patient preference," Headache: The Journal of Head and Face Pain, vol. 40, no. 5, pp. 371-372, 2000.

[26] J. Pascual, R. Muñoz, and R. Leira, “An open preference study with sumatriptan $50 \mathrm{mg}$ and zolmitriptan $2.5 \mathrm{mg}$ in $100 \mathrm{mi}-$ graine patients," Cephalalgia, vol. 21, no. 6, pp. 680-684, 2001.

[27] E. Weidmann, J. Unger, S. Blair, C. Friesen, C. Hart, and R. Cady, "An open-label study to assess changes in efficacy and satisfaction with migraine care when patients have access to multiple sumatriptan succinate formulations," Clinical Therapeutics, vol. 25, no. 1, pp. 235-246, 2003.

[28] C. G. H. Dahlöf, M. Linde, and E. Kerekes, "Zolmitriptan nasal spray provides fast relief of migraine symptoms and is preferred by patients: a Swedish study of preference in clinical practice," The Journal of Headache and Pain, vol. 5, no. 4, pp. 237-242, 2004.

[29] R. B. Lipton, F. M. Cutrer, P. J. Goadsby et al., "How treatment priorities influence triptan preferences in clinical practice: perspectives of migraine sufferers, neurologists, and primary care physicians," Current Medical Research and Opinion, vol. 21, no. 3, pp. 413-424, 2005.

[30] J. Schoenen, J. Pascual, S. Rasmussen, W. Sun, C. Sikes, and J. Hettiarachchi, "Patient preference for eletriptan $80 \mathrm{mg}$ 
versus subcutaneous sumatriptan $6 \mathrm{mg}$ : results of a crossover study in patients who have recently used subcutaneous sumatriptan," European Journal of Neurology, vol. 12, no. 2, pp. 108-117, 2005.

[31] M. Láinez, S. Evers, E. Kinge et al., "Preference for rizatriptan 10-mg wafer vs. eletriptan 40-mg tablet for acute treatment of migraine," Cephalalgia, vol. 26, no. 3, pp. 246-256, 2006.

[32] A. Dowson, M. Bundy, R. Salt, and S. Kilminster, "Patient preference for triptan formulations: a prospective study with zolmitriptan," Headache: The Journal of Head and Face Pain, vol. 47, no. 8, pp. 1144-1151, 2007.

[33] F. I. Díez, A. Straube, and G. Zanchin, "Patient preference in migraine therapy," Journal of Neurology, vol. 254, no. 2, pp. 242-249, 2007.

[34] M. Lantéri-Minet, H. Allain, P.-L. Druais, G. Meric, and S. Troy, "Evaluating patient satisfaction with specific migraine therapy based on initial treatment expectations: the PAX study," Current Medical Research and Opinion, vol. 26, no. 2, pp. 465-472, 2010.

[35] M. Bartolini, M. A. Giamberardino, C. Lisotto et al., "A double-blind, randomized, multicenter, Italian study of frovatriptan versus almotriptan for the acute treatment of migraine," The Journal of Headache and Pain, vol. 12, no. 3, pp. 361-368, 2011.

[36] J. M. Gonzalez, F. R. Johnson, M. C. Runken, and C. M. Poulos, "Evaluating migraineurs' preferences for migraine treatment outcomes using a choice experiment," Headache: The Journal of Head and Face Pain, vol. 53, no. 10, pp. 1635-1650, 2013.

[37] A. F. Smelt, M. A. Louter, D. A. Kies et al., "What do patients consider to be the most important outcomes for effectiveness studies on migraine treatment? Results of a Delphi study," PLoS One, vol. 9, no. 6, Article ID e98933, 2014.

[38] H. Ha and A. Gonzalez, "Migraine headache prophylaxis," American Family Physician, vol. 99, no. 1, pp. 17-24, 2019.

[39] J. L. Jackson, E. Cogbill, R. Santana-Davila et al., "A comparative effectiveness meta-analysis of drugs for the prophylaxis of migraine headache," PLoS One, vol. 10, no. 7, Article ID e0130733, 2015.

[40] X.-M. Xu, Y. Liu, M.-X. Dong, D.-Z. Zou, and Y.-D. Wei, "Tricyclic antidepressants for preventing migraine in adults," Medicine, vol. 96, no. 22, p. e6989, 2017.

[41] M. Linde, W. M. Mulleners, E. P. Chronicle, and D. C. McCrory, "Valproate (valproic acid or sodium valproate or a combination of the two) for the prophylaxis of episodic migraine in adults," Cochrane Database of Systematic Reviews, vol. 6, Article ID CD010611, 2013.

[42] M. Laura and W. Anne, "Acute migraine headache: treatment strategies," American Family Physician, vol. 97, pp. 243-251, 2018.

[43] W. J. Becker, T. Findlay, C. Moga, N. A. Scott, C. Harstall, and P. Taenzer, "Guideline for primary care management of headache in adults," Canadian family physician Medecin de famille canadien, vol. 61, no. 8, pp. 670-679, 2015.

[44] W. J. Becker, "Acute migraine treatment," Continuum: Lifelong Learning in Neurology, vol. 21, pp. 953-972, 2015. 